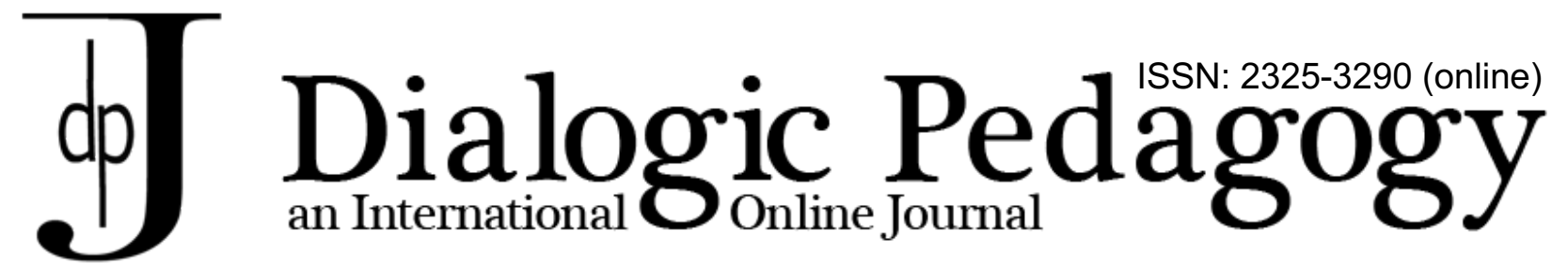

\title{
Dialogic pedagogy in graduate teacher education research advisement: A narrative account of three teacher educators
}
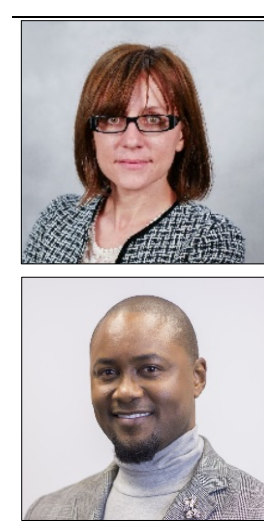

Victorina Baxan

University of Toronto, Canada

Andrew B. Campbell

University of Toronto, Canada

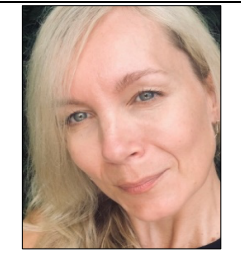

Joanne Pattison-Meek

University of Toronto, Canada

\begin{abstract}
Research methods courses often tend to focus on transferring technical information to students rather than offer a more dialogical approach to learning (Barraket, 2005; Kilburn et al., 2014). By drawing on the concept of self-study (Bullough \& Pinnegar, 2001), through personal journals and retrospective reflections, this paper explores learning activities introduced in three teacher education graduate research methods courses to support student learning beyond the mastering of research skills or techniques. Narratives of three teacher educators illustrate how teacher candidates can dialogically reflect on research-related topics with peers, bring questions forward for discussion in class and online, apply their emerging technical research skills through collective analysis of a situation, and grow collective knowledge. Teacher candidates recognize the importance of research in their work, although their passion for conducting research is influenced by varied constraints, including research design, programmatic and personal limitations.
\end{abstract}

Key terms: graduate teacher education, dialogic teaching and learning, graduate research advising, research methods, reflection, self-study.

Dr. Victorina Baxan is a lecturer in the Master of Teaching Program at the Ontario Institute for Studies in Education (OISE), University of Toronto. Victorina's teaching currently focuses on research methods in education. In addition to her teaching in the graduate teacher education program in Canada, Victorina taught undergraduate foreign language courses in Moldova. She also had the opportunity to provide academic writing advising to undergraduate and graduate students in her role with the OISE Student Success Centre. Victorina holds a PhD from OISE. Her current research interests focus on graduate teacher education, dialogical engagement in teaching and learning, research writing, and diversity issues in education.

Dr. Joanne Pattison-Meek is a faculty member in the Master of Teaching Program at the Ontario Institute for Studies in Education (OISE), University of Toronto. She teaches courses including Educational Research Literacy and Fundamentals of Teaching and Learning. Prior to joining the MT Program in 2018, Joanne was a former high school teacher, school board curriculum leader, and program lead for a school board research department. She received her PhD in Curriculum Studies and Teacher Development from 


\section{Dialogic pedagogy in graduate teacher education research advisement Victorina Baxan, Joanne Pattison-Meek, Andrew B. Campbell}

OISE in 2016. Her research interests are rooted in rural education and democratic pluralist citizenship teaching and learning, and dialogic pedagogy in teacher education research courses.

Dr. Andrew B. Campbell (DR. ABC) is a graduate of the University of Toronto, with a PhD. in Educational Leadership, Policy, and Diversity. He is presently an Adjunct Assistant Professor at Queens University in the Professional Master of Education (PME) Online and a faculty member at the University of Toronto, in the Master of Teaching (MT) program, in the Department of Curriculum Teaching and Learning (CTL). He is an Ontario Certified Teacher (OCT) and has taught at all levels of the education system for the last 25 years, in Jamaica, Bahamas, and Canada. His research and teaching focus on issues of Equity \& Inclusion, Educational leadership, Black LGBTQ+ Issues, Teacher Education, and Teacher Performance Evaluation.

\section{ded}

\section{Introduction}

Future teachers need to develop an understanding of educational research and how research is an inherent part of a teacher's work (Moulding \& Hadley, 2010). Increasingly, graduate teacher education programs include a research project as part of the requirements to complete the program (e.g., Ontario Institute for Studies in Education, McGill University). Despite the interest in graduate teacher education (Assunção Flores, 2017; Davies et al., 2013; Kitchen \& Petrarca, 2016; Petrarca \& Kitchen, 2017; Baxan \& Broad, 2017), there is little research on how research methods are taught, how students actually learn research methods (Earley, 2014; Kilburn et al., 2014; Wagner et al., 2011), and how the research supervisory relationship is envisioned and enacted by research instructors and their students. Trial-anderror and reliance on peers seems to be the norm for developing a pedagogy for teaching research methods (Earley, 2014; Kilburn et al., 2014), while guiding students to complete their research projects is often informed by a research advisor or supervisor's own experience as a graduate student (Henderson, 2018).

In this article, three teacher educators present individual narratives as research advisorsinstructors. These narratives evolved from our collective pedagogical discussions in search of approaches to move from "transferring technical information about research methods" to teacher candidates, to a more dialogical approach to learning, where technical skills are mastered through "reflection and collective analysis" (Barraket, 2005, p. 67). We present and discuss ways in which dialogic teaching principles (Alexander, 2018) guided our individual approaches to support teacher candidates in graduate teacher education research methods courses. The introduction of these dialogic activities was motivated by our shared challenges of guiding teacher candidates to develop an instrumental understanding of the process of conducting research, enhancing their awareness of the complexities of conducting educational research, and learning how to analyze and write up research - all of which aimed to increase teacher candidates' agency in their own learning. The main question that guided our research was: How do we support teacher candidates to dialogically navigate the complexities of conducting educational research and own their learning as they bring their graduate research projects to fruition?

Since teacher candidates' research projects were embedded in the courses that we taught, we conceptualize our research advising as teaching (Boud \& Lee, 2005; Boud \& Costley, 2007). Our research advisory roles are unique in many ways compared to more traditional research advising practices: our graduate students have relative freedom to select a research topic; students can only select either an interview-based study or document analysis; the duration of the research project is confined within the research course timeframe; and, most of what can be termed as research advisor-student interactions, occur during class time due to the relatively large number of students in a graduate research methods course (between 25 and 34 for each course). Writing from our perspectives as research advisors, we aim to provide insights into how we approach advising as teaching in qualitative research methods courses. 


\section{Dialogic pedagogy in graduate teacher education research advisement Victorina Baxan, Joanne Pattison-Meek, Andrew B. Campbell}

We start the paper with an overview of the graduate teacher education program in which we are all instructors. Next, we describe what brought us to teaching research courses to provide insights into what experiences inform our work as research advisors. The review of the literature that we then present does not aim to be a systematic review of past research, but rather a deeper reading (Kilburn et al., 2014) of studies that connected to our research, guided by our collective reflections. Next, we introduce the readers to our methodology. We then proceed with a description of how we conceived teaching research methods by presenting our individual narratives of approaches to teaching/advising, and how we enacted them, as well as our reflection on the process. We conclude with an overview of major learnings and next steps in our research that emerged from our collaborative work on advising as teaching. Ideas that we discuss in this paper are interpreted through our own lenses and the inferences that we present are completely our own and may not fully represent the perspectives of the authors we cite or those of the graduate program where we teach.

\section{Master of Teaching (MT) Program Context}

We are research instructors in the Master of Teaching (MT) Program at the Ontario Institute for Studies in Education (OISE) of the University of Toronto. The MT Program is a two-year graduate level teacher education program that leads to both a Master of Teaching degree and teacher certification in the province of Ontario (Canada). Our teacher candidates work on a full-time basis to complete 18 half-courses (two of which are research methods courses), and 4 practice teaching placements (each 4 weeks in length).

As stated in the MT program vision statement, "Teaching excellence and scholarly research are the mutually reinforcing pillars of the Master of Teaching program. The program prepares candidates to become outstanding teachers and leaders who consult, critique, create, and mobilize educational research" (OISE, 2019). Thus, an important part of our work as research instructors is to support teacher candidates' identities as teachers who are also researchers. Teacher candidates complete the Educational Research 1 course in their first year of study (36 hours in-class), having a focus on research literacy. This introductory research course centers on epistemology and reflexivity, teachers as theorists-intellectuals-researchers, research paradigms, qualitative methodologies and methods, and practitioner inquiry. In addition to learning about these key topics, candidates review the research literature in an area of education that interests them and write a 15-20 page literature review or position paper. This is a carefully scaffolded process whereby candidates participate in a double-blind peer review. Each candidate uploads a copy of their draft research paper to peerScholar (a specialized learning management platform intended for peer assessment) and in turn, reviews two papers written by other MT year 1 teacher candidates. Research instructors guide candidates through how to provide constructive feedback on the work of their peers (e.g., quality of writing, conceptual clarity) as well as how to respond to critique, implement revisions, and produce a final polished research paper.

In the second year of the program, as a requirement of the Educational Research 2 graduate seminar (also 36 hours in-class), teacher candidates conduct a small scale qualitative research study, using either semi-structured interviews with educators or document analysis, on a topic related to teaching and learning. This course pays particular attention to research design, data collection, data analysis, and knowledge sharing, and is designed to support teacher candidates throughout the various stages of the research journey. For example, teacher candidates receive feedback on the discrete stages of the analysis process so that they can implement instructor suggestions and continue to refine their findings. By the end of the course, candidates produce a 15-20 page research paper that describes their research study and findings, which they present at the annual end-of-year Master of Teaching research conference. Content and instruction in both year 1 and 2 research courses prepare teacher candidates to engage dialogically with and contribute to knowledge in their fields of interest. 


\section{Dialogic pedagogy in graduate teacher education research advisement Victorina Baxan, Joanne Pattison-Meek, Andrew B. Campbell}

This research project emerged from a conversation we had about our pedagogical choices in planning our research courses and how they affected the way teacher candidates engaged with initial research concepts, developed an inquiry question, examined empirical research articles and wrote a final research paper. As relatively new to teaching research methods courses, we started to have regular discussions around our teaching practices after each class, and soon became increasingly drawn to the idea of a self-study and understandings of how we can better support our graduate students/teacher candidates during the research components of their graduate teacher education program. Our meetings and continued reading of the literature on teaching research methodology took us in the direction of exploring how a dialogic approach to teaching and learning (Alexander, 2018) may support students to construct their own meaning of the research process. We had three voices on our project that shared a deep commitment to student learning and research, although we came to this work with varied past experiences. Our own personalities and teaching experiences were different in so many ways that our conversations did not have the risk of becoming redundant. We constantly reframed the questions we asked ourselves which led to new lines of inquiry. Having different perspectives and voices on the team helped us to avoid having a master narrative and kept the dialogic nature of our work alive (Bakhtin, 1981), although we did preserve a similar interest in dialogic teaching and learning. In what follows we provide a brief overview of the experiences that shaped our collaborative work and conversations.

\section{Victorina}

I obtained my teacher certification outside of Canada and worked as a secondary school teacher and university instructor of English as a foreign language. I became a research advisor-instructor in the graduate teacher education program after completing my doctorate in Canada. It was my passion for teaching and research, coupled with my interest in teacher education, as well as a teaching opportunity that arose that brought me to teaching research methodology in a graduate teacher education program. At the time of writing this paper, I was in my fourth year teaching research courses to future teachers in a researchbased graduate teacher education program. I had been holding a number of administrative roles at the university level while teaching in the MT program.

\section{Joanne}

Similar to you Victorina, I arrived at the role of research instructor in the faculty of education at OISE after having worked at the secondary school level. I was a high school Geography and Politics teacher for ten years in Ontario while simultaneously completing my doctoral work in education. I was an instructional program leader in the research department of a large school board in southern Ontario (Canada) just prior to teaching at OISE. In that role I was responsible for building research literacy among school board staff at various levels of the organization. I was drawn to the MT program's emphasis on preparing teachers to engage in reflective inquiry with the goal of effecting change in their classrooms, schools, and wider communities.

\section{Andrew}

Coming to the MT program here at OISE felt like a natural next step for me. I did my teacher education program in Jamaica and came to this research instructor work after 25 years as a classroom teacher and educator in various roles. For the last 12 years I have worked part-time in postsecondary education as a college lecturer, online facilitator and adjunct assistant professor, all in educational leadership and teacher preparation programs. As someone who completed graduate studies (masters and doctoral studies) as a part-time student while being a full-time elementary classroom teacher, I have a firsthand account of the value teacher-researchers can bring to the creation of educational inquiry and knowledge to inform practice. Knowing the power and value of teacher research is a major motivation for why I was so attracted to teaching research methods in the program. 


\section{Dialogic pedagogy in graduate teacher education research advisement Victorina Baxan, Joanne Pattison-Meek, Andrew B. Campbell}

\section{Victorina}

Joanne and Andrew, it seems that we all came to the work of research instructors from different locations. This said, we all obtained our teacher certification prior to pursuing doctoral studies, as well as taught in Grade 1-12 (elementary and secondary) classrooms, albeit in different contexts and varied lengths. While pursuing doctoral studies, all three of us were holding teaching or administrative appointments at either Grade 1-12 schools or postsecondary institutions.

\section{Joanne}

Indeed, Victorina. The teaching experiences at both secondary and postsecondary levels, as well as similar journeys while conducting graduate research seem to have shaped our collaborative work. Furthermore, through supporting in-school leadership teams in improvement planning with respect to analysis of student and school level data (e.g., developing school improvement plans, analysis of standardized test results, and school self-assessments), as well as facilitating professional learning for classroom teachers focusing on research-informed practice and decision-making (e.g., organizing teacherinquiry projects, assessing/monitoring student well-being needs), I became increasingly interested in opportunities to teach in teacher education programs.

\section{Andrew}

I do believe that these similarities of interest and lived experiences also allowed us to build trust and collegiality. For me, hearing these stories, it felt like you both understood my journey a bit more than others, and also valued the work that I was doing. This allowed me to see you both beyond your teaching methods, and fostered a further spirit of inspiration for this work. I also come to the work of a research instructor from a place as a teacher-researcher myself who has engaged in action research, self-study, and other phenomenological inquiries knowing these ways of finding out can support the change that we often want to see in our schools. Like you Joanne, doing workshops for years in Jamaica, Bahamas and Canada, I have interacted with teachers and educational leaders who continuously seek answers for everyday issues within and outside of formal schooling. I have seen the delight with which they would engage in academic readings and activities knowing that the information provided data and critical analysis of the very issues they face.

\section{Literature Review}

Equipping learners with research skills is an increasing priority in university-level programs (Hughes, 2019; Kilburn at al., 2014). Such skills are essential to function well in the education programs, but also to prepare for a challenging landscape of job opportunities and demands. The idea that teacher candidates' work is research-informed, but that they also become researchers and have an inquiry stance is increasingly part of teacher education programs' goal (Davies et al., 2013; Kitchen \& Petrarca, 2016; Petrarca \& Kitchen, 2017). Rudduck's (1985) position that "attitudes and habits supportive of research need to be encouraged in courses of initial teacher education which are all too often dominated by concerns of short-term survival rather than long-term professionalism" (p. 281) remains valid today.

There are numerous benefits for research-based teacher education: it shapes teachers' view of teacher-research and of themselves as enquiring practitioners; it prepares them to become more successful readers of professional literature and allows for more competent uses of research literature; it exposes them to the discourse of the profession, both conceptually and linguistically; it equips them with academic skills required for studies at doctorate level; future teachers explore how to use research to deal with problems of practice; learning to adopt a reflective, inquiry stance helps become part of a professional 


\section{Dialogic pedagogy in graduate teacher education research advisement Victorina Baxan, Joanne Pattison-Meek, Andrew B. Campbell}

routine; and future teachers develop an ability to identify ethical issues when conducting research (Crawford-Garrett et al., 2015; Reis-Jorge, 2007).

Reflexivity is an important element in research-based teacher education programs, and is integral to the learning of research methods with an inquiry stance. Reflexivity, it is argued, provides students opportunities to not only reflect on the research practice, on the methods they learn, the context of their learning and teaching, but also to help them recognize their own assumptions about research (Kilburn et al., 2014; Cox, 2012; Thien, 2009). Reflexivity can also help graduate students inquire into their own anxieties and motivations for conducting research, as well as their interactions with past research (DeLyser et al., 2012; Hsiung, 2008; Kilburn et al., 2014). Kilburn at al. (2014) maintain that "more broadly, fostering a critical and reflective disposition towards methods is arguably an important aim of methodological learning in itself" (p. 203).

Increasingly, graduate teacher education programs in Canada include a research project as part of the requirements to complete the program (e.g., Ontario Institute for Studies in Education; McGill University; Baxan \& Broad, 2017). By engaging in research projects, it is assumed that teacher candidates improve their perception of preparedness for research later in their careers (Shaw et al., 2011, cited in Kilburn, 2014). A question that is under-researched and is part of an ongoing debate in teaching research methods is how research capability can be taught or developed for the envisioned learning benefits to be realized (Hughes, 2019).

\section{Ways research methods are taught and how students are supported in their research process}

There is little research on how research methods are taught and how students actually learn research methods (Jacobsen et al., 2018; Wagner et al., 2017; Earley, 2014; Kilburn et al., 2014). Trialand-error and reliance on peers seems to be the norm for developing a pedagogy for teaching research methods (Earley, 2014; Kilburn et al., 2014). Integral to the latter is the question of how we can facilitate the development of research skills and support students, including teacher candidates, through the process of designing and conducting a research study, and write their final paper (Albrighta, 2012). Byman et al. (2009) posits that such work could start with learning qualitative, quantitative, and mixed methods, and practice research with small activities and assignments from the very beginning of their studies. Kilburn et al (2014) posits that:

the teaching approaches discussed in the literature mirrored three complementary and inter-related pedagogical goals: the first goal sought to make the research process visible by actively engaging students in the aspects of the methods at hand; the second sought to facilitate learning through the experience of conducting research; and the third sought to encourage critical reflection on research practice (p. 197).

Yet another strategy that may help graduate students understand research methods concepts, acquire research skills and progress well in their research is scaffolding student research (Hughes, 2019). Such scaffolding can be supported by a coherent program design that allows students to develop a clear picture of their learning journey, as well as develop a learning plan that includes personal progress, and short- and long-term goals (Fung, 2017; Hughes, 2019). A coherent program design though, needs to be further supported by a 'feed forward" (Hattie \& Timperley, 2007) and ipsative approach to feedback. The notion of "feed forward" refers to evaluation and feedback on student research development. Students would engage with such feedback and apply it to future work or research activities in a cumulative way (Hattie \& Timperley 2007; Hughes, 2019). Hughes $(2017,2019)$ maintains that, "an ipsative approach to 


\section{Dialogic pedagogy in graduate teacher education research advisement Victorina Baxan, Joanne Pattison-Meek, Andrew B. Campbell}

feedback, where learners receive information on their progress from a comparison of current work with previous work, enables learners to develop at their own pace" (p. 399). Scaffolded assignments coupled with ipsative feedback and support helps students achieve major milestones in their research (Hughes, 2011, 2014, 2019).

Peer feedback is another strategy that has proved useful in graduate research, given the increased workloads for supervisors (Saeed \& Ghazali, 2019). Although graduate students are hesitant initially to engage in peer feedback, when supervisors/advisors provide mentoring and instructional strategies to support such work, challenges are easier to overcome (Saeed \& Ghazali, 2019). Peer research groups, as an informal pedagogy which is based on peer learning (Aitchison, 2003; Aitchison \& Lee, 2006), allow for learners to scaffold each other and construct their knowledge in writing (Saeed \& Ghazali, 2019; Yu \& Hu, 2017).

Notwithstanding the many strategies above, as the capacity to engage with and undertake research requires a "combination of theoretical understanding, procedural knowledge and mastery of a range of practical skills" (Kilburn et al., 2014, p. 191), the teaching and learning of research poses many challenges.

\section{Challenges of teaching research methods courses}

Research studies that focus on teaching and learning research methods identify a number of challenges, such as conceptualising disciplinary and generic research skills and identifying threshold concepts, as well as supporting the research development of all students, not only those who may continue as researchers (Hughes, 2019). Research also shows the task of writing up research tends to be a burden on students' routine, and many struggle to produce formally designed research projects to meet the criteria imposed by academic regulations (Reis-Jorge, 2007; Löfström, 2012). There is also a tension between highly structured forms of research that research courses may foster and the consequent demands of time and expertise that it imposes on researchers (Kotsopoulos, Mueller \& Buzza, 2012). The flexibility of choice for a final project (in terms of methodology) may be problematic in terms of supervision, validation, and assessment (Reis-Jorge, 2007; Löfström, 2012; Kotsopoulos, Mueller \& Buzza, 2012).

Other research shows that challenges for teaching research methods include capturing and monitoring student learning over time, as well as identifying those instances when students are unable to progress due to difficulties associated with understanding certain research concepts (Hughes, 2019). Hughes maintains that, "knowledge may be troublesome because it requires a student to take on a new identity. This identity may be about becoming part of the community of scholars in a discipline and thinking like them" (p. 397). In such instances, as students engage with new concepts and ideas, they feel insecure and uncertain. Such instances of 'being stuck' may lead to delays in progressing in one's work, "for example, if students are unable to formulate sensible questions, then they will not be able to plan appropriate data collection. Getting 'stuck' in this way is likely to make research unappealing to students" (Hughes, 2019, p. 397). One way to address this issue is to scaffold student learning across the entire graduate program (Brew, 2013; Hughes, 2019) and to revisit difficult research concepts over time (Hughes, 2019). Kilburn et al. (2014), by drawing on past research, point to the conclusion that an approach that is more akin to academic supervision may yield a better understanding for students than knowledge transmission in the classroom. However, academic supervision may not always be feasible in a research course, given the high number of graduate students enrolled in them.

\section{Role of research advisor-instructor}

While doctoral and research-based master's programs embed a more clearly defined research trajectory and planning process, managing and evaluating the research development is often left to the 


\section{Dialogic pedagogy in graduate teacher education research advisement Victorina Baxan, Joanne Pattison-Meek, Andrew B. Campbell}

individual student and their advisor (Hughes, 2019). Supervisor roles in a research-based program need to be dynamic (Saeed \& Ghazali, 2019). The supports offered to graduate students through research-related courses may not be sufficient, and the workload of supervisors may not allow for increasing the one-onone consultations (Aitchison 2009; Wilmot 2016; Saeed \& Ghazali, 2019). While research supervision in degrees that focus on research outcomes such as a doctoral and Master's theses has been given more attention, there is little research on the role of research advisors in undergraduate and graduate research projects (Boud \& Costley, 2007).

The expectations of course instructors as research advisors is increasingly shifting to comprise the advisement of large groups of students who need to complete research projects within the timeframe of research courses. Compared to research training and research outcomes associated with doctoral and Master's theses, the research projects completed as part of coursework tend to have a much wider range of learning outcomes, rather than research outcomes (Boud \& Costley, 2007). Such roles take the academic advisors/instructors beyond the more familiar teaching role. Bould \& Costley (2007) posit that there is a need to distinguish between teaching as advising, and the more traditional supervisory role:

Supervision is a term typically used in postgraduate research degrees in universities following the British tradition. It suggests a particular form of relationship between staff member and student that is often intense and extended. It also has connotations of direct oversight and 'top-down' power relations between supervisor and supervisee ( $p$. 120).

Boud and Costley (2007) thus advocate for a redefinition of the roles of academic staff who support research project work. In our experience, there seems to be an increasing need for redefining such roles in courses that bring together students from varied disciplinary backgrounds and a wide range of research interests. Compared with a traditional supervisory relationship where the supervisor has a greater understanding of the knowledge content of the project, the advisor's knowledge does not normally fit the research focus or disciplinary background of all the graduate students in their class. One way to address this question in our courses, was to draw on the notion of dialogic teaching and learning that posits that meaning is co-constructed, both among graduate students, as well as between them and their instructor.

In our roles as research advisors-instructors, and as we started to share tensions that we encountered in our teaching, we began to be drawn to Alexander's (2006; 2008; 2010; 2018) principles of dialogic teaching and learning. What attracted us to these principles was the notions of 'negotiation' and 'facilitation' of meaning. Furthermore, since our graduate teacher education program followed a cohortbased model, Alexander's (2018) work that "draws on transnational and cross-cultural classroom research" helps us to better understand "how classroom cultures, values and interactions are variously shaped by collective, communitarian and individualist emphases in accounts of social relations and by culturally located stances on human development, the nature and acquisition of knowledge and the act of teaching" (p. 3). Alexander (2018) also posits that every classroom is unique, and as such, every teacher would need to develop a broad repertoire of dialogue-based pedagogical skills and strategies and draw on it as necessary to facilitate the development of such dialogic repertoires among their students. Agency is fundamental in Alexander's (2018) framework, and one of the primary goals in our research courses was to develop graduate student agency for meaning making. We recognize that Alexander's (2018) principles comprise only one of the components of the dialogic teaching framework that he proposes, which also include justifications, repertoires and indicators. As we began exploring Alexander's (2006; 2018) work, we adapted the principles that he identified as guiding elements in our teaching, as follows:

- Collective: instructor and teacher candidates (TCs) address learning tasks together, whether as a group or class; 


\section{Dialogic pedagogy in graduate teacher education research advisement Victorina Baxan, Joanne Pattison-Meek, Andrew B. Campbell}

- Reciprocal: instructor and TCs listen to each other, share ideas and consider alternative viewpoints;

- Supportive: TCs articulate their ideas freely, without fear of embarrassment over 'wrong' answers; and they help each other to reach common understandings;

- Cumulative: instructor and TCs build on their own and each other's ideas and chain them into coherent lines of enquiry;

- Purposeful: classroom talk, though open \& dialogic, is structured with specific learning goals in view.

Dialogic teaching or advising for us comprises a repertoire of opportunities and classroom organization on which we draw flexibly according to purpose and situation, and which become dialogic when they are informed by principles of collectivity, reciprocity, support, cumulation, purposefulness, criticality, meaningfulness, and accountability (Alexander, 2006, 2018; Michaels et al., 2008). To further dialogic engagement, answers during such opportunities need to spark new questions and invite participants to go beyond reporting someone else's thinking (Nystrand et al., 1997; Alexander, 2018).

\section{Methodology}

We draw on the concept of self-study (Bullough \& Pinnegar, 2001) as our methodology and posit that through reflection and interactions of self-as-teacher educator with others who have a commitment to the education of student teachers, there is potential for powerful change in the pedagogies we use. Bullough and Pinnegar (2001) state that "the aim of self-study research is to provoke, challenge, and illuminate rather than confirm and settle" (p. 20). Self-study has been defined in various ways by many researchers, based on their role, practice and the purpose of the study. The type of study being undertaken and its focus, such as self as a teacher, self as a researcher of their own teaching, the self as a researcher of teacher education, and the self as a researcher of self-study often define how self-study is positioned (Samaras \& Freese, 2009). Self-study, as Ikpeze (2019) notes, "is a necessary pedagogical exercise that can improve teaching and learning in teacher education learning contexts. Self-study enables teacher educators to conduct intentional and systematic inquiry into their own practice that yields knowledge about practice" (p. 107). The intention of this research is guided by these very foundational ideas of self-study. As faculty, we ourselves had many questions about the research process as we engaged our students. In our teaching, we see the need to provoke and challenge our own and our graduate students' ways of thinking about research.

The desire to see our students develop as teacher researchers, fueled by their successes and varied personal constraints, as well as the deliberate dialogic conversations we held amongst ourselves as instructors, fostered the need to engage in self-study. This desire was both personal and professional for all of us. We concur with Mahani (2019) who notes that we need to situate ourselves in the inquiry and draw on our experiences as educators, while also collaborating with colleagues coming from different backgrounds and who bring different lenses to self-study. Therefore, the three of us started to share classroom practices. We participated in self-reflection and engaged in courageous reflective and reflexive feedback from each other. This collegial collaboration was a very strong part of the process. During the many conversations we had about the course, we continuously shared ideas and 'good' practices. Additionally, we developed a strong bond and higher degrees of trust. The vulnerability that was needed for this kind of work followed, and with that openness, came deeper insights in what we shared. This vulnerability sparked additional layers of dialogue. We knew we would share information about our classroom practices, but also about how we approached research ourselves. We asked ourselves, What are the ideas we are passionate about? How do we engage ourselves as teacher researchers? In what aspects of our teaching do we need support? How do we share those struggles and tensions with our students? Samaras and Freese (2009) maintain: 


\section{Dialogic pedagogy in graduate teacher education research advisement Victorina Baxan, Joanne Pattison-Meek, Andrew B. Campbell}

self-study focuses on improvement on both the personal and professional levels.Self-study builds on the personal processes of reflection and inquiry and takes these processes and makes them open to public critique. Self-study is not done in isolation, but rather requires collaboration for building new understandings through dialogue and validation of findings. Self-study research requires openness and vulnerability since the focus is on the self. And finally, self-study is designed to lead the reframing and reconceptualizing of the role of the teacher (p. 5).

As we engaged in dialogue and continuously received feedback and encouragement from each other, we were able to share and build on each other's practices of teaching research methods. This allowed us to make pedagogical changes to our work. More and more we confirmed the relational nature of selfstudy. Markides' (2019) words reflect well how we felt during this process, "Inherently, the praxis of selfstudy is an integral part of teacher education. Teaching practice grows from an ongoing cycle of experience, reflection, and further action. In this way, I become the site of my study. Contrary to the notation of self as being individual-focused, self-study is of a relational nature" (p. 36).

It was therefore through pedagogical dialogue that we became at ease with tensions (and successes) that arose in our teaching. The process of classroom dialogue that we in turn adapted in our teaching of research methods, both face-to-face and online, seemed to allow students to gain the confidence to ask questions, share their own knowledge and expertise without being seen as threatening to those who did not have the knowledge, engaged in peer review, and garnered the skills needed to be more critical and reflexive. The dialogic engagement, thus, became part of our self-study, as well as integral to our teaching research methods, research advising, and development as teacher educators.

Self-study is characterized by multiple methods of data collection, depending on the focus of the study, and meaning making is the norm (Loughran, 2007). As we engaged in this research, we collected data through personal journals, retrospective reflections, email exchanges, and critical incidents. During this process, we acted as critical friends to validate our findings (Loughran, 2007). As faculty who are new to self-study, we were moving to a place where we valued stories and narratives within the rigor of research, and we had to come to grips with varied levels of authenticity and vulnerability, if we were to truly share our professional self.

One of the limitations of this study is that we were not able to visit each others' classes to see the various methods at work. This was something we talked about and agreed would add additional layers of reflection as we would be observers and critical friends within the actual dialogic space that we create for our students. We would be able to see and hear the dialogue from a different vantage point and provide that additional feedback to each other. Scheduling demands and ethical considerations prevented us from advancing this idea. We, however, have not abandoned it, and will focus on collaboratively deciding what this process may look like as part of our ongoing self-study project. Although we did not visit each other classes yet, we started to use each other's strategies for dialogic engagement that we describe in what follows. We also acknowledge that we have not yet formally invited and included the voices of our students to comment on how they are actually experiencing our dialogic approaches.

\section{Research Advisor-Instructor Narratives}

As research advisors-instructors, we sought to examine how we facilitate teaching and learning of research methods in a graduate teacher education program, and describe instructional activities that aimed at fostering dialogical engagement with research concepts and ideas and at co-construction of meaning. Our narratives also aimed to provide insight into the teaching as advising role. We drew on Alexander's (2006; 2018) dialogic teaching principles to help frame our advising role as dialogical and encompassing multiple dialogical encounters: dialogue among teacher candidates through activities that we as research 


\section{Dialogic pedagogy in graduate teacher education research advisement Victorina Baxan, Joanne Pattison-Meek, Andrew B. Campbell}

advisors design, dialogue between teacher candidates and research advisors, and dialogue among research advisors. In what follows we present our narratives around these three dialogical encounters. We recognize that these narratives present findings from the initial stages of our self-study and that drawing on Alexander's principles is just the beginning of a deeper exploration of dialogic teaching as a field of inquiry.

\section{Dialogue among teacher candidates}

\section{Victorina}

One of the instructional activities I have used in my research courses to foster dialogic engagement is the 'World Café' conversation model (The World Café Community Foundation, 2015). The activity's goal is to help teacher candidates (TCs) engage with research methods readings and concepts. TCs sign up for roles called 'World Café Conversation (WCC) Hosts' for a given class, while the rest of the class act as 'Ambassadors of Meaning'. Each time we meet, we have 4-6 WCC Hosts who facilitate two progressive rounds of conversation lasting approximately 20 minutes in small circles. In the beginning of the course, I would facilitate a discussion of dialogic principles (Alexander, 2006; 2018) that would guide the WCC activity. It is the Host's role to remind participants of the critical issue of the day that serves the overarching purpose of the conversation. The Hosts decide on how they want to organize the dialogue (e.g., using various question prompts, minds-on activities, online tools such as mentimeter, etc.), taking into account the dialogic guiding principles. Upon completing the initial round of conversation, the Hosts remain in the circle, while the Ambassadors carry key ideas, themes and questions into new conversations/circles. After two rounds of conversation, I would initiate debriefing, which involves sharing discoveries and insights in a whole group conversation. The Hosts post their discussion preparation notes to our course online community (called Pepper) in advance of each class. After facilitating the reading discussion, each Host posts their response/reflection on the activity to the online community. It is in these conversation-style or dialogic encounters that collective knowledge seems to grow and possibilities for action emerge.

\section{Joanne}

A key question that guides the development of my research courses in our graduate teacher education program is: how can I make educational research relevant and meaningful to support teachercandidates' dialogic engagement with course material? As a research instructor, I tend to draw on my previous professional experiences as a classroom teacher, and a research program leader in a local school board when designing dialogic activities. I feel it is important to recreate (model) school-based scenarios for my teacher-candidates to navigate as future teacher-researchers. So, I always strive to offer candidates insights into what research might actually look like in schools for the course to be useful and inform candidates' future professional practice. For example, how and why is research collected in schools? How is this research shared and acted upon, and by whom? These school-based insights are also used as a means to inform teacher-candidates' planning of their graduate research projects. To realize these objectives, I created Teacher-Research(er) in Context (TRIC) as a pedagogical approach.

I introduce TRIC moments as opportunities to invite students to dialogically reflect on a researchrelated topic with peers ('talking it out') and apply their emerging technical research skills through collective analysis of a situation. To provide one example of a TRIC in action, I present teacher candidates with a type of (fictitious) data set commonly distributed and discussed among staff in schools: graph data depicting students' declining sense of belonging in school, as they progress from Grades 4 through 12 . After providing a very brief description of the image, I task teacher-candidates, in small learning groups, to collectively reflect on the data piece and respond to the following questions:

- What are you seeing/understanding?

- What questions are you still left with? 


\section{Dialogic pedagogy in graduate teacher education research advisement Victorina Baxan, Joanne Pattison-Meek, Andrew B. Campbell}

- Drawing on your knowledge and understandings of qualitative research, how might you go about responding to your lingering questions?

Imagining that this information originated from the school in which they work, teacher candidates then collectively develop qualitative research plans to dig deeper into the quantitative sense of belonging data as teacher-researchers. For example, conducting student focus groups to qualitatively understand the data from student perspectives, or designing a classroom-based assignment in their teachable subject area that elicits students' reflections on their sense of belonging in the school.

\section{Andrew}

In my teaching of research courses, I wanted to ensure that students own the discussions and that dialogue would be more fluid. The approach I am using both in class and online is called "Questions I still have..." Teacher candidates have the option to ask questions and reflect on these questions when their peers have responded, and this seems to be effective and useful from the feedback I received from them in one on one meetings. They would often refer to these very discussions. The intention is to "maximise the power of the classroom discussion talk to enhance students' engagement and learning" (Alexander, 2018). The process has a few levels and layers of questions and responses.

Before each physical class, teacher candidates are asked to complete assigned readings and post a response within the designated discussion forum in our course learning management system (LMS), Pepper. They are always asked to post one question for discussion and to respond to two questions. This process allows teacher candidates to ask questions, respond to questions, observe the kinds of questions being asked, and develop their skills in framing questions and respond to questions by applying their knowledge and understanding of the course material. Over the academic year, I have observed growth in how teacher candidates frame questions. Through my observations, I noticed growth especially in their increased use of research terminologies. As their instructor, this serves as a form of needs assessment, as I am able to review their questions before class, see the kind of thinking that is happening based on their various responses, and observe their level of engagement. This impacts my lecture planning and class activities. It fosters a level of satisfaction that their ideas and questions are being seen and valued, but more so, in being responded to.

During class lecture, the teacher candidates form self-selected groups to discuss various issues and complete activities. As a part of the discussion process, each group member is expected to ask questions that they have in relation to the issue or activity. However, there is an understanding that these questions allow for students to engage each other in any part of the research process they are at. All other members of the group must respond to those questions. These responses are not necessarily direct answers to the questions. They are responses, which can range from agreeing with their peers, providing additional insights, sharing a personal story or example or even asking a question. They are not restricted to provide a researched answer - they are encouraged to sustain the dialogue.

Finally, after the class has ended, teacher candidates have 24 hours to reflect on what happened in class, go online in our LMS system, and post another question, after which they are required to respond to any two questions of their peers. In a class of 32 candidates, they have the opportunity to read 31 other questions and an average of 62 responses. So many ideas, concepts, and concerns can be addressed in this way, and it enhances a student's ability to engage in reflective practice. It also helps candidates to appreciate collegiality, the impact of peer review in research and to confirm their role as knowledge creators. This approach supports the various levels of background knowledge they bring to the research process. My intention is thus to provide a space for reflective and reflexive review since the questions remain on the course in the LMS and we can look back as a class to what we wanted to know and what we now know. 


\section{Dialogic pedagogy in graduate teacher education research advisement Victorina Baxan, Joanne Pattison-Meek, Andrew B. Campbell}

\section{Victorina}

Andrew and Joanne, it seems that all the three approaches that we have used in our teaching are quite structured, and that we as instructors are quite involved as facilitators. We do highlight what is most important for us as instructors as we designed these activities. For me, one of the most important aspects in learning is engaging deeply and thoughtfully with research literature. Such literature, often termed course readings, and engagement with specific texts is a requirement in each of the research courses that we are teaching, as you know well. The WCC activity that I described intends to help engage students in discussions that would lead to arriving at certain understandings about research collectively. Such activities aim to help teacher candidates co-construct meaning or knowledge about research concepts and terms or engage in what Wells (1999) calls 'dialogic inquiry.' The dialogic engagement during the WCC activity is collective, reciprocal, and supportive, but rarely cumulative (Alexander, 2018). Although we do come together for larger discussions and we address the major concepts and topics that we are to cover in a given session, I find that this is not enough. To me, reading is at the core of acquiring the language/terms/concepts that they need to engage in further dialogue in class. A question that I am asking myself as I am planning for classes is, "How can the dialogue delve deeply if students are not yet comfortable engaging with concepts and with each other's comments, primarily because they do not yet have a grasp of the vocabulary specific to research methodology and have not yet established a certain level of trust to express their ideas freely?"

Joanne

Victorina, I appreciate the challenge you share above regarding some students' hesitancy to engage in dialogue with peers because they might not be comfortable with some research concepts. I face this challenge as well. In response, I tend to create situational opportunities for students to connect to course content on a more personal level - to humanize the research experience, so they may feel less intimidated by the strangers in the room. I have had some success with the Teacher-Researchers in Context approach I describe earlier because it provides dialogic opportunities for teacher candidates to recognize their role in the data story/ies unfolding in their future classrooms, schools, and wider communities. I align my goals with Alexander's (2018) principles as follows:

- Engaging teacher candidates in open, yet structured critical conversations about the use of education research in school settings (Collective);

- Inviting teacher candidates to practice critical listening, while building on each other's ideas and various viewpoints in supportive, small groupings (Reciprocal, Supportive, Cumulative).

- Drawing on and applying teacher candidates' emerging understandings of course research concepts (Purposeful);

It is fascinating for me to move around the room and listen to candidates' interactions unfold. Candidates appear engaged: the volume of voices in the room dials up, bodies lean forward toward the center of their discussion groups, horizontal cross talk is visual and audible. School-level data almost always seems to invite even the quietest students to share, affirm, and/or contest ideas with their peers. In these moments, those candidates who arrive to the course with little to no research training have an opportunity to listen, ask questions, and learn from those candidates who bring research experience with them to the course. This reciprocal sharing of ideas (Alexander, 2018) provides an opportunity for candidates to deepen research literacy as well as to consider alternative perspectives when analyzing data. These conversations do not always happen this freely without guided support from myself. However, using this approach is one means for me to prioritize authentic learning experiences - something I see as vital to connect candidates dialogically to research learning. 


\section{Dialogic pedagogy in graduate teacher education research advisement Victorina Baxan, Joanne Pattison-Meek, Andrew B. Campbell}

Andrew

Alexander (2018) posits that "Classrooms remain places where it is the teacher who asks most of the questions, so a dialogically informed questioning repertoire must allow for the possibility that students too will have questions to ask and must be encouraged and if necessary, train them to do so" (p. 9). I believe that when lecture and readings about research concepts and skills prompt dialogue, it often limits what can be asked, and students sometimes shy away from asking since they feel what they have may be unrelated. This has been my experience teaching research methods at the undergrad level for several years. This limits the interaction and classroom discussions, both face to face and online becomes laborious, in my view. There are however opportunities to measure growth and learning. As part of the activity I described, I also review the online posts that may have fewer responses or the most responses (often stemming from an interesting debate), and I use that in class as part of the lecture. This brings a high level of relevance to the activity, and the candidates do not seem to feel it is useless or busywork. I see a number of benefits for my activity: value for collaboration and corroboration in research practice; opportunity to share expertise; opportunity to break down research concepts in more manageable bits for increased understanding; increased skills in peer-review process; confirmation of their role as knowledge creators; more refined reflections on class readings; better use of reflection to inform pedagogical decision-making. But, I must add, there is work to be done to get them to that place of asking questions that goes deeper than just searching for immediate responses to a problem they are facing in order to "unstuck" themselves.

\section{Victorina}

Indeed, Andrew and Joanne, the activities you both described seem to allow for so many opportunities for dialogue. I was wondering how these activities worked across the cohorts that you have been teaching. In my case, year 2 teacher candidates do not usually appear too sensitive to how their peers may perceive their input and whether they have mastered well the research concepts and the research terminology. From my observations, this is because year 2 teacher candidates tend to be more comfortable with each other since they would have been in the same cohort for longer. The dialogue thus tends to be more supportive (Alexander, 2018), compared to other principles (e.g., collective, reciprocal, cumulative or purposeful) (Alexander, 2018). Also, because in their year 2 teacher candidates have to engage in their own data analysis, that is to work on data reduction and move from codes to categories to themes (Saldana, 2008), they seem to engage with course concepts and readings before class more consistently. This became evident as I was listening to their dialogical interactions in class. Year 2 TCs seem thus to be more purposeful (Alexander, 2018) in their in-class dialogic activities as they have specific learning goals in view (e.g., identify codes in data sets). Through retrospective reflection, I came to see that the dialogical engagement in my classes is highly influenced by the level of comfort TCs have with research methodology concepts, as well as with each other, and how they perceive the usefulness of research readings for immediate application in their research process.

Joanne

I agree, Victorina. Teacher candidates do seem to appear more comfortable discussing research concepts and asking questions openly in year 2 of the program compared to year 1 . The year 1 strangers in the room I refer to earlier tend to disappear and morph into supportive allies as they work to complete their research projects in year 2. I also notice distinct differences as I move between different research classes in the same program year (e.g., I sometimes instruct three year 1 classes concurrently). Each individual class has a distinct personality that may require me to adjust my pedagogical approach slightly to achieve the learning goals. For example, some year 1 classes seem habitually chatty - they easily connect socially on the first day of the program - and tend to be receptive to dialogic activities. Diversely, the social chemistry in other classes is not as natural, which may constrain dialogue. These situations require me to work a bit harder to nurture stronger relationships and trust among teacher candidates so 


\section{Dialogic pedagogy in graduate teacher education research advisement Victorina Baxan, Joanne Pattison-Meek, Andrew B. Campbell}

they may feel comfortable enough to engage dialogically with their peers (e.g., facilitating weekly conversation circles to practice speaking in front of a group; organizing in-class potlucks to build a sense of community).

Andrew

I smile when I listen to you both because this is also my experience. It is also a somewhat proud moment for me when I see the growth and level of trust they build and the willingness to share knowledge and offer each other feedback. Victorina, I like your use of the term supportive as I observe the marked level of support that comes with their growth. An example of when this is obvious is during my one-on-one sessions in year 2, where some students would appear at my office in pairs or threes, declaring they are aware it is time slated for one person, but emphasized that through their discussion they realised they had the same question or were wrestling with the same concern, and then (often jokingly) asked to see me at the same time. I have found this to be very encouraging as what I see is not only trust and support, but they are developing the skills to question research intentions and ideas among themselves.

As we hope the above narratives showed, while each of our dialogic interactions differs in strategy, we all share the same goal in our teaching: to use a dialogic approach to nurture students' capacity to construct their own meaning of educational research. These approaches, however, pose common challenges to our role as research advisor-instructors. We often share among ourselves that facilitating a dialogic approach to teaching and learning requires less rigidity in how we allocate time in each class session. For example, we may arrive to a 3-hour class with a fixed agenda. However, when dialogic interactions seem to be furthering students' interest and learning in course content, we realize that we need to be flexible and consider providing more time for these activities than initially planned. Such realizations have challenged us to adapt our practices in-the-moment to meet students' learning needs. In this way, we are extending ourselves to be less bound by the rigid knowledge transmission models that we may have experienced as graduate students ourselves. To let go of a rigidity of practice can be a discomforting process.

\section{Dialogue between teacher candidates and research advisor-instructor}

Victorina

One of the strategies I use to gain a better understanding of my graduate students' progress is to provide them with opportunities to meet with me one-on-one. Most of these meetings occur outside our class time, and they can last from 10-15 minutes to half an hour or more, depending on teacher candidates' (TCs) needs and my availability. Such meetings may be initiated by me or by the TCs. Such meetings allow me to better understand what concepts or ideas remain unclear, as well as provide encouragement and guidance for supports outside the course, such as academic advising or teaching assistants. Meetings with year 1 graduate students tend to focus on how to select a research topic and develop a research question. To help them think about the research topic, I often ask what brought them to teaching and why they selected our graduate teacher education program. Year 2 TCs tend to require more advising around data reduction and analysis, and this is in line with one of the goals of the research course. We often discuss the messiness of the research process, as well as its iterative process. I often ask graduate students to bring a chunk of their anonymized data for us to look at together. We start by revisiting concepts such as code, category and theme (Saldana, 2008) that are part of our in-class dialogic activities, and then independently code a paragraph or two of data/text. As we compare our units of analysis, we discuss how our positionality, disciplinary backgrounds, mastering of research concepts, and past experiences with research affect the way we select codes, categories and arrive at themes. We often discuss the role of reflexivity in the research process, as well as the importance of having a critical friend for peer support and feedback. I tend to encourage TCs to select a critical friend in year 1 and work together for the entire 


\section{Dialogic pedagogy in graduate teacher education research advisement Victorina Baxan, Joanne Pattison-Meek, Andrew B. Campbell}

duration of the graduate program. This allows TCs to learn about each other's research in more substantive ways, as well as allows for continuity in peer feedback.

Given the number of students in a given class, as well as my adjunct teaching/advising status, it is not often possible to allot time frequently for one-on-one meetings. For this reason, I provide a space in the course learning management system (LMS), called Pepper, for such interactions to occur. I named this space "Writing to Learn." Students in my class are invited to upload their work in progress in that folder/space. I advise them to upload work every time we meet for our classes, when they reach a milestone in their research (often linked to major assignments in the course), as well as when they complete work on a certain aspect or section of their final research paper (e.g., introduction, positionality statement). When TCs would like me to provide feedback on a certain piece, they would send me an LMS message or email. The folder thus serves two purposes: uploading work in progress for instructor feedback, as well as tracking their own research progress. For the purpose of tracking their research process and development of the final paper, I advise students not to delete any draft submissions. This allows them to go back to that folder and see, for example, how their research questions evolved, or how the sections of the paper transformed over the course of the academic year. Such submissions and comparisons of prior and current work allow me and the teacher candidates to visualize the scaffolded aspect of the process, realize the messiness involved in research, as well as help them feel proud of completed work.

The frequency of teacher candidate submissions varies across and within the cohorts I teach. While many welcome such opportunities, others may look at it as increasing an already onerous workload. In addition, many students expect that as a research advisor-instructor I would provide feedback on every single submission. To address this expectation, at the start of each class I provide graduate students an opportunity to share updates and learnings about their research journey, and any questions that they may have. In turn, I share what I am observing as strengths and challenges related to teaching and learning in our course, based on TCs engagement in in-class activities, as well as through reading teacher candidates' 'Writing to Learn' submissions. This allows me to address common concerns, and emphasize that many researchers encounter both similar and distinct rewards and challenges when conducting research.

Joanne

Similar to you Victorina, I do meet with TCs one-on-one outside classes. As research instructors, we recognize that students arrive to our courses with a range of research knowledge, from novice to doctoral level understandings, as well as holding diverse and often contrasting perceptions about research in general. Before I meet with graduate students one-on-one, as a first step toward engaging in meaningful dialogue with my students, as well as facilitating dialogic interactions among students, I commence the research course with a reflective-narration activity. I ask candidates to consider and respond to the following questions:

(i) Please share any of your previous experiences with research (if you have limited experience with research, it's ok! this is important to share!)

(ii) When you hear the term research, what does it mean to you?

(iii) In your opinion, what is the role of research in teaching (if any)?

(iv) When you hear the term teacher-researcher, what does it mean to you?

(v) What are some of the opportunities and challenges that you foresee for yourself personally as you enter our research course?

As a take-home assignment, I task candidates to create a 4-7 minute voice recording to capture their responses to the above questions (e.g., via a cell phone app). Candidates link their responses, as audio files, to a QR (quick response) code, and then print out their code on a piece of paper to bring to 


\section{Dialogic pedagogy in graduate teacher education research advisement Victorina Baxan, Joanne Pattison-Meek, Andrew B. Campbell}

class and display along the walls of our classroom. I usually designate one hour of class time for candidates to listen to the various research stories around the room while wearing headphones, accessing each narration via $Q R$ reader apps on their electronic devices.

I had various intentions for facilitating this type of reflective audio library approach. First, it provides me with an opportunity to hear and assess each candidate's experiences with research more generally, their understandings of teacher-researchers, and any concerns they had entering the course. These reflective-narrations provide me with talking points (which I record in a spreadsheet) to engage in dialogue with each of my candidates while inside or outside of class. For example, during a break mid-class, or a face-to-face meeting during my office hours, I might follow up with teacher candidates who made particular comments or asked questions in their recordings. This demonstrates that I take an interest in their research journey (yes, I actually listened!), and helps to build a strong(er) instructor-student relationship from which deeper dialogue can develop. I also listen for patterns across audio narratives and incorporate these into my lesson planning (e.g., attending to expressions of discomfort with qualitative research from students with quantitative backgrounds). I take much time to do this because I genuinely want candidates to know that I care and am invested in their MT research journeys. Inviting teacher candidates to reflect on and share their previous experiences with (and current perceptions regarding) research also provides us, as course instructors, with opportunities to (re)shape our pedagogical approaches as I indicated earlier on. Additionally, this approach is one way to ready teacher candidates to step into dialogue with their peers. Through inviting them to listen to the research stories of others, candidates have an opportunity to reflect on their own beliefs about research, and who they are as emerging researchers themselves, by trying to understand the research experiences of others.

Victorina

Joanne, as you know, I started to include the activity you describe in my classes as well this year, as a result of our collaborative work. In fact, this academic year I did this activity twice: in the beginning of the course and then in the end of the course to help graduate students reflect on their journey and on how their understanding of research changed. As we displayed the QR codes on the walls, I observed how TCs were listening to recordings put together months apart. As part of the next steps in our self-study project, we can delve deeper into graduate students' experiences with this approach following the ethics approval. This activity also proved very useful when we reached the transcription phase in the research project in my courses. TCs transcribed their recording and then they shared and discussed in class best strategies for faster and more accurate transcription.

\section{Andrew}

Similar to both of you, I established dedicated sessions/times for each teacher candidate to meet with me to discuss their progress. This has been a most effective practice and rewarding practice with year two students. They each get 10 minutes. Each session is planned with a focus, but teacher candidates are informed, and even encouraged to come to the session with as many questions and/or concerns they may have based on where they are in the research process. The nature of the dialogue honors the learning pattern of the individual student and their own journey in the research process. My intention is also to build trust and to allow them to become a bit less stressed in a process that demands very rigid deadlines, thus "the goal is to create a warm, relaxing, and comfortable environment where trusting communication is able to flourish" (Prewitt, 2011, p. 192). During this period, I get more insight into who they are, their research background, their ideas surrounding qualitative research, the personal issues they are dealing with, what challenges they are facing in the research process, and how I can best direct them. From these dialogues I have also observed a lack of confidence many candidates have in their research abilities and again, a lack of "passion" for a real area of interest. Those who have that genuine interest in a cause connected to 


\section{Dialogic pedagogy in graduate teacher education research advisement Victorina Baxan, Joanne Pattison-Meek, Andrew B. Campbell}

social justice, educational change and student well-being, in general, are the ones who are doing the better work and making faster strides in my view.

These meetings vary on a very wide continuum. There are teacher candidates who need one question answered or one point of clarity and will be done with our dialogue in less than five minutes. There are also those candidates who seem to have a lesser grasp of the concepts to be engaged with and the dialogue takes on a somewhat 'lecturette' feature. There are then those who used this dialogue as a means of reassurance and confirmation that they are doing what is required, and finally there are those whose dialogue has nothing to do with the focus of the day or their actual research paper - they needed that time to just talk. The conversations get into them sharing personal issues impacting their research directly and indirectly. These topics range from matters of personal or family illness, death of a family member, to joyful news of an engagement or new job. What is shared is based on the trust they develop for me as an instructor. This trust is invaluable and assists me in offering feedback that is honest. When the trust and comfort level is high, for me, there has been a marked correlation in how I have provided feedback and how they receive the feedback. When they feel less judged, they are more open to the feedback they receive.

This process allowed me to be more intentional in listening. As a classroom teacher for over twentyfour years, teaching at the elementary level, and in most of my years, in a very hierarchical educational system, I have developed a listening skill in order to respond. This listening is content driven and result oriented. The purpose of students' question is to get clarity from me, and the purpose of my response is to provide an answer. In these dialogues, I have discovered and found a new value for just listening to listen. Teacher candidates in some cases, did not need answers or clarifications, they needed someone to listen to their ideas and thoughts without even contributing with an actual word. My depositions of care and empathy, my body language, the offering of a tissue or simple gesture of a thumbs-up became the dialogue - enough dialogue.

As we engaged in dialogue with graduate students/teacher candidates either through in-person or online activities, pre-recorded answers to questions pertaining to their research journey or understanding of research, or one-on-on meetings, what transpired for us is the element of care and opening ourselves to a less structured approach in our teaching and interactions. The trust that graduate students had to develop with their peers extended to us as research-advisors. We all felt that the one-on-one meetings, even if brief, helped build that trust that led to more in-depth dialogical encounters with both peers and instructors/research advisors as we hope will become more evident in the next section of the paper.

\section{Dialogue among research advisors-instructors}

The three of us, Victorina, Joanne, and Andrew, we all bring distinct yet complementary contributions to our self-study. Although we completed our doctorate degrees in Canada, we all grew up and completed our undergraduate and masters degrees, started our teaching careers and worked in a number of contexts: Jamaica, Japan, Moldova, Sweden, United Kingdom, The Bahamas, USA, China and Canada. These experiences contributed to rich conversations and ideas, as well as varied approaches to teaching and learning. Our self-study journey to date has been increasingly emotional and rewarding. As we shared our teaching strategies and approaches, we came to realize that at times well-intended instructional strategies appeared to add to the students' workloads and cause anxiety; that any dialogic engagement, either between students or ourselves, requires genuine collaboration; that students responded well to guidance, but needed more autonomy when carrying out their group activities. We feel connected through shared stories about our research courses, as well as our passion for teaching and research. As we analyzed our retrospective reflections, critical incidents that we shared in person, as well as email exchanges, we found a few threads, which we discuss below. 


\section{Dialogic pedagogy in graduate teacher education research advisement Victorina Baxan, Joanne Pattison-Meek, Andrew B. Campbell}

\section{Victorina}

One of the recurring themes that I noticed in our discussions is that we all commented on the fact that the teacher candidates in the program that we teach come from varied disciplinary backgrounds. I find that this impacts their understanding of research and understanding of the writing conventions associated with qualitative research. What I have noticed over the course of my teaching/advising and our research advisor discussions is that those teacher candidates who come from the Sciences, as well as the field of Psychology, tend to favor quantitative research methodology and the language they use tends to reflect that (e.g., 'subjects' instead of 'participants', 'results' versus 'findings'). I also find that students who have a Sociology background tend to engage more critically with the readings, as well as have no trouble understanding the research concepts or writing conventions that we discuss. As research advisorinstructor, I spend time engaging TCs in discussions about the differences between quantitative and qualitative research, but I find that these conversations need to be iterative. We need to go back to those differences repeatedly during the course of the year, especially in the first year of the graduate teacher education program. Also, I find that because TCs have to grapple with the requirements and expectations of a graduate level program and of a teacher education program, they are often overwhelmed by the workload. I tend to spend time reminding TCs about the importance of devising a schedule for completing work for our course and that a lot of self-directed learning is involved. If I were to compare the year 1 and year 2 courses, I find that by year 2, TCs reach a degree of maturity in terms of the understandings of research concepts and research process that helps them with the more advanced research work, although this varies from year to year. Year 2 TCs tend to appreciate the scaffolding that happens in Year 2 and think that the assignments build on each other, and help them with completing work overall, as well as with their dialogic encounters with their peers and research instructor-advisor.

\section{Joanne}

Indeed, Victorina, the educational background and research experiences that graduate students bring to their work affect their engagement in our classrooms. One of the biggest challenges I face in teaching the year 1 course, and to a lesser extent in year 2, is the pushback I experience from those teacher candidates who do not regard qualitative research as "real research." Some candidates who arrive from the Sciences are quick to point out what they believe to be inaccuracies built into qualitative research because of its non-scientific, non-statistical reliance on researcher subjectivisms. These students want/need to see results that can be verified and duplicated, which is near impossible, they say, when factoring in the variability of researcher bias within the data, compounded by the response bias built into the data provided by its human source. Sometimes the comments I field come across as hostile and I often feel myself on the defensive. This is another reason why I developed the Teacher-Researchers in Context activities (described above). This approach gently challenges those students from quantitative backgrounds to try on and apply a set of qualitative lenses and experience data differently. By year 2, as you Victorina also notice, the resistance quiets somewhat. However, I wonder if my role as instructor, wielding final mark authority, ultimately silences the questioners. Or, do they genuinely see the value in qualitative research after all of the dialogic work we pour into the year 1 course?

As indicated earlier, I spent many years as a classroom teacher, followed by a period as a research leader in a school board research department. In these roles I seemed to have endless opportunities to engage and connect with my colleagues, for example, at planning meetings, professional development sessions, departmental meetings, and of course, the much-loved Friday after-work socials. Being new to instructing in a faculty of education, I struggled. I felt like a new teacher again (e.g., lesson planning, familiarizing myself with department technology, logistics, who's who?) and looked for occasions to socialize and debrief with fellow MT instructors. I was relieved when you, Victorina, put out a call for those 


\section{Dialogic pedagogy in graduate teacher education research advisement Victorina Baxan, Joanne Pattison-Meek, Andrew B. Campbell}

interested in joining a research instructor self-study group. To say that my professional growth has evolved as a result of our discussions after more than one year together is a gross understatement.

Andrew

Joanne and Victorina, the dialogue shared among us for me too was a major source of professional development through collaboration and collegiality. We were able to speak openly about our concerns with the course, teacher candidates and other related issues. This opportunity allowed us to build professional and personal bonds. You do not get to spend this much time with others and not get to know them on various levels. In those moments of sharing we are more than just research instructors. We see each other. We brought our identities into the conversations and these allowed us to build trust, which in turn provided the foundational trust necessary to share, be vulnerable and reflective. Because we come from different spaces in research and careers, these exchange of ideas and insights were significantly beneficial. The multiplicity and differences between our teaching styles, lived experiences, and professional journeys were also beneficial factors.

We were able to share our concerns without feeling judged or inadequate. For me, I shared my concerns around the lack of readiness from many of the TCs to engage in real research dialogue since they lack some fundamental knowledge about qualitative research and many at that time, did not complete the readings as they should. There was also a difference in vocabulary with those who came into the program with a quantitative background and as such, there is much work to be done in that fundamental area and scope and sequence of what is taught in year one. It is hoped that teacher candidates come to the program with a certain level of exposure and fundamentals skills in conducting research. However, many are yet to understand the independent nature of research - this is an orientation and mindset that is vastly lacking and therefore impacts the amount of feedback that is being requested by the students. Some lack the disposition of a qualitative researcher - not many have a "passion or cause" they wish to investigate. This also impacts their ability to be reflective and reflexive in their writing and articulate a solid positionality in their work. Based on these sharing of concerns, we were able to share our instructional strategies which allowed for further feedback. We borrowed ideas from each other and would share what it looked like in our various classes. I walk away with insights and questions that are of value, having shared my own ideas with colleagues who not only value the work that I am doing, curious themselves, but also who are often living the same experiences. In this collegial dialogue, the three of us offer our opinions, suggestions, and push back with our own questions. We engaged in an authentic dialogical process.

As we reviewed our email exchanges and the critical incidents that we shared, a major thread in our dialogic instructor-instructor encounters focused on the interactions among students during the activities we presented, and what affected teacher candidates' overall engagement and motivation. As research advisors-instructors we noticed that some teacher candidates, especially in year 1 , saw little value in learning about research methods. These TCs, at that stage in their journey, may not yet see the connection between what they learn in research courses and their future career or higher studies, such as a doctorate. This challenge is in line with Preissle and Roulston (2009) who found that learner qualities and motivations played a significant role in how they engaged with research concepts and ideas. Another factor that affected teacher candidates' engagement in dialogic activities seemed to be their level of confidence stemming from their prior disciplinary background and conceptions of what constitutes engagement. As we worked with concepts and ideas, we emphasized the messiness and uncertainty which are a part of the research process (Hammersley, 2012; Hughes, 2019). 


\section{Dialogic pedagogy in graduate teacher education research advisement Victorina Baxan, Joanne Pattison-Meek, Andrew B. Campbell}

Another thread related to challenges when engaging with course concepts. These seemed to arise in the form of anxiety due to the overall workload in the program, as well as workload specific to the research courses. Such anxiety may also have led, from our observations and retrospective reflections on critical incidents in our course, to a form of aversion towards research methods. Aversion toward research methods is not uncommon (Baloglu \& Zelhart, 2003). However, through points of discussion, time to reflect, online sharing, peer responses and modelling, students were able to start developing a sense of ownership for their learning. Online responses seemed to allow for more freedom to post, reflect, and share a more even distribution of student voices. Other struggles that we noticed related to being unfamiliar with qualitative research and language conventions due to prior disciplinary affiliations. As research advisors-instructors we also found that TCs need more one-on-one support outside the class time, but such support is not sustainable due to the types of appointments we hold (e.g., adjunct faculty) and time constraints due to the large number of students in our classes.

\section{Learnings from our Collaboration and Next Steps}

The collaborative self-study project that our research team engaged in for the past two academic years yielded valuable learnings that have informed our teaching, and will guide us to improve our research advising practices. Given the wide range of research experiences that teacher candidates bring to our research methods courses, as research advisors-instructors, we will continue to scaffold our teaching/advising to meet the diverse learning needs of our students. We hope that guiding teacher candidates to co-construct research knowledge through a dialogic approach, having Alexander's dialogic teaching principles (2018) as a start, will support their teacher research capacity for working in school settings and beyond.

As we move forward in our work, one of our goals still remains to find ways to increase graduate students' readiness for dialogue, as well as further encourage dialogue among TCs, TC-instructor, and whole class. We also need to build more instructional activities that foster trust in TCs' own and peer contribution to dialogue, as well as help teacher candidates to embrace their own professional teacherresearcher voice. The quality of dialogue needs further development. The range or repertoire of dialoguebased pedagogical skills and strategies that we have is still expanding and we find that some strategies that worked really well with one cohort do not do well with others. Getting to know who the graduate students in our courses are and how they respond to dialogic opportunities will help inform which instructional strategies to use.

Findings from this study contribute to the literature on dialogic pedagogy in graduate research methods teaching and learning. The study also shows the potential for a range of dialogic opportunities for graduate students to initiate inquiries, engage in constructive peer discussions and co-construct meaning with peers and research advisors-instructors, as they work towards completing their research projects. Next steps would be to invite graduate students' voices about how they experience the opportunities that we described.

\section{References}

Albrighta, K., Petrulisb, R., Vasconcelosc, A., \& Woodd, J. (2012). An inquiry-based approach to teaching research methods in Information Studies. Education for Information, 29, 19-38. https://doi.org/10.3233/EFI-2010-0912

Aitchison, C. (2003). "Thesis Writing Circles." Hong Kong Journal of Applied Linguistics, 8(2), 97-115.

Aitchison, C. (2009). Writing Groups for Doctoral Education. Studies in Higher Education, 34(8), 905-916. 


\section{Dialogic pedagogy in graduate teacher education research advisement Victorina Baxan, Joanne Pattison-Meek, Andrew B. Campbell}

Aitchison, C., \& Lee.A. (2006). Research writing: Problems, and pedagogies. Teaching in Higher Education, 11(3), 265-278.

Alexander, R. (2006). Towards dialogic teaching: Rethinking classroom talk (3rd ed.). Cambridge, UK: Dialogos.

Alexander, R. (2008). Culture, dialogue and learning: Notes on an emerging pedagogy. In N. Mercer \& S. Hodgkinson (Eds.), Exploring talk in schools (pp. 91-114). London, UK, SAGE Publications.

Alexander, R. (2010). Speaking but not listening? Accountable talk in an unaccountable context. Literacy, 44(3), 103-111.

Alexander, R.J. (2018). Developing dialogue: Genesis, process, trial. Research Papers in Education, 33(5), 361-398. https://doi.org/10.1080/02671522.2018.1481140

Assunção Flores, M. (2017). Practice, theory and research in initial teacher education: International perspectives. European Journal of Teacher Education, 40(3), 287-290. https://doi.org/10.1080/02619768.2017.1331518

Bakhtin, N. (1981). The dialogic imagination. Austin, TX: The University of Texas Press.

Baloglu, M. \& Zelhart, P. (2003) Statistical anxiety: A detailed review. Psychology and Education, 40, 2737.

Barraket, J. (2005). Teaching research methods using a student-centered approach? Critical reflections on practice. Journal of University Teaching and Learning, 2(2), 64-74. Retrieved from http://ro.uow.edu.au/jutlp/vol2/iss2/3

Baxan, V., \& Broad, K. (2017). Graduate initial teacher education: A literature review. OISE Master of Teaching Visioning Process Resource. Available at http://www.oise.utoronto.ca/mtvisioning/UserFiles/File/Literature Review Chapter 1 Final.pdf

Boud, D., \& Lee, A. (2005). Peer learning' as pedagogic discourse for research education. Studies in Higher Education, 30(5), 501-516. https://doi.org/10.1080/03075070500249138

Boud, D. \& Costley, C. (2007). From project supervision to advising: New conceptions of the practice. Innovations in Education and Teaching International, 44, 119-130.

https://doi.org/10.1080/14703290701241034

Brew, A. (2013). Understanding the scope of undergraduate research: A framework for curricular and pedagogical decision-making. Higher Education, 66, 603-618.

Bullough, R., \& Pinnegar, S. (2001). Guidelines for quality in autobiographical from of self-study research. Educational Researcher, 30(3), 13-21.

Byman, R., Krokfors, L., Toom, A., Maaranen, K., Jyrhämä, R., Kynäslahti, H., \& Kansanen, P. (2009). Educating inquiry-oriented teachers: Students' attitudes and experiences towards research-based teacher education. Educational Research and Evaluation, 15(1), 79-92. https://doi.org/10.1080/13803610802591808

Cox, R. D. (2012) Teaching qualitative research to practitioner-researchers. Theory Into Practice, 51(2), 129-136.

Crawford-Garrett, K., Anderson, S., Grayson, A., \& Suter, C. (2015). Transformational practice: Critical teacher research in pre-service teacher education. Educational Action Research, 23(4), 479-496. https://doi.org/10.1080/09650792.2015.1019902 


\section{Dialogic pedagogy in graduate teacher education research advisement Victorina Baxan, Joanne Pattison-Meek, Andrew B. Campbell}

Davies, L.M., Anderson, M., Deans, J., Dinham, S., Griffing, P., Kameniar, B., \& Taylor, D. (2013). Masterly preparation: Embedding clinical practice in a graduate pre-service teacher education programme. Journal of Education for Teaching, 39(1), 93-106. https://doi.org/10.1080/02607476.2012.733193

De Lyser, D., Potter, A. E., Chaney, J., Crider, S., Debnam, I., Hanks, G., Hotard, C. D., Modlin, E. A., Pfeiffer, M., \& Seemann, J. (2012) Teaching qualitative research: Experiential learning in groupbased interviews and coding assignments. Journal of Geography, 112(1), 18-28.

Earley, M. A. (2014). A synthesis of the literature on research methods education. Teaching in Higher Education, 19(3), 242-253. https://doi.org/10.1080/13562517.2013.860105

Fung, D. (2017). A Connected Curriculum for Higher Education. London: UCL Press.

Hammersley, M. (2012) Is it possible to teach social research methods well today? Discussion paper presented at HEA Social Sciences Teaching and Learning Summit: Teaching Research Methods, University of Warwick, June 21-22.

Hattie, J., \& Timperley, H. (2007). The power of feedback. Review of Educational Research 77(1), $81-$ 112. https://doi.org/10.3102/003465430298487

Henderson, E. F. (2018). Anticipating doctoral supervision: (Not) bridging the transition from supervisee to supervisor. Teaching in Higher Education, 23(4), 403-418. https://doi.org/

Hsiung, P.-C. (2008). Teaching reflexivity in qualitative interviewing. Teaching Sociology, 36(3), 211-226.

Hughes, G. (2019). Developing student research capability for a 'post-truth' world: Three challenges for integrating research across taught programmes. Teaching in Higher Education, 24(3), 394-411. https://doi.org/10.1080/13562517.2018.1541173

Hughes, G. (2011). Towards a personal best: A case for introducing ipsative assessment in higher education. Studies in Higher Education, 36(3), 353-367. https://doi.org/10.1080/03075079.2010.486859

Hughes, G. (2014). Use of self-referential (ipsative) feedback to motivate and guide distance learners. Open Learning, 29(1), 31-44. https://doi.org/10.1080/02680513.2014.921612

Ikpeze, C. (2019). Negotiating identity in a relational pedagogy: A cross-cultural perspective. In E. Lye (Ed.), Fostering a relational pedagogy: Self-study as transformative praxis. (pp. 104 -115). Netherlands: Leiden Brill Sense.

Jacobsen, M., McDermott, M., Brown, B., Eaton, S., \& Simmons, M. (2018). Graduate students' researchbased learning experiences in an online Master of Education program. The Journal of University Teaching \& Learning Practice, 15(4), 1-18. Retrieved from https://ro.uow.edu.au/jutlp/vol15/iss4/4/

Kilburn, D., Nind, M. \& Wiles, R. (2014). Learning as researchers and teachers: The development of a pedagogical culture for social science research methods? British Journal of Educational Studies, 62(2), 191-207. https://doi.org/10.1080/00071005.2014.918576

Kitchen, J., \& Petrarca D. (2016). Approaches to teacher education. In J. Loughran \& M.J. Hamilton (Eds.), International handbook of teacher education (pp.137-186). Volume I. Spinger.

Kotsopoulos, D., Mueller, J., \& Buzza, D. (2012). Pre-service teacher research: An early acculturation into a research disposition. Journal of Education for Teaching, 38(1), 21-36.

https://doi.org/10.1080/02607476.2012.643653 


\section{Dialogic pedagogy in graduate teacher education research advisement Victorina Baxan, Joanne Pattison-Meek, Andrew B. Campbell}

Loughran, J. (2007). Researching teacher education practices: Responding to the challenges, demands, and expectations of self-study. Journal of Teacher Education, 58(1), 12-20.

Löfström, E. (2012). Students' ethical awareness and conceptions of research ethics. Ethics \& Behavior, 22(5), 349-361. http://dx.doi.org/10.1080/10508422.2012.679136

Markides, J. (2019). Being Indigenous in the Indigenous education classroom: A critical self-study of teaching in an impossible and imperative assignment. In E. Lye (Ed.), Fostering a relational pedagogy: Self-study as transformative praxis (pp. 35 -44). Netherlands, Leiden: Brill Sense.

Mahani, S. (2019). A self-study of culturally relevant pedagogy in a higher education institution in the United Arab Emirates. In E. Lye (Ed.), Fostering a relational pedagogy: Self-study as transformative praxis (pp. 82 -92). Netherlands, Leiden: Brill Sense.

McGill University [Programs leading to teacher certification page]. (n.d.). Retrieved June 1, 2019 from https://www.mcgill.ca/dise/progs

Michaels, S., O'Connor, C., \& Resnick, L.B. (2008). Deliberative discourse idealized and realized: Accountable talk in the classroom and civic life. Studies in Philosophy and Education 27(4), 283297.

Moulding, L. R., \& Hadley, K.M. (2010). Graduate students' understanding of educational research in a Master of Education Program, New Horizons in Education, 58(1), 43-52.

Nystrand, M. (1997). Opening dialogue: Understanding the dynamics of language and learning in the English classroom. New York, NY: Teachers College Press

Ontario Institute for Studies in Education (OISE). [Master of Teaching about our program page]. (n.d.). Retrieved June 10, 2019 from https://www.oise.utoronto.ca/mt/About Our Program.html

Ontario Institute for Studies in Education (OISE). [Master of Teaching Vision Statement]. (n.d.). Retrieved June 10, 2019 from https://www.oise.utoronto.ca/mtvisioning/Home.html

Petrarca, D., \& Kitchen, J. (Eds.). (2017). Initial teacher education in Ontario: The first year of foursemester teacher education programs. Canadian Association for Teacher Education/Canadian Society for Studies in Education. Ottawa: Canadian Association of Teacher Education. Retrieved from http://cate-acfe.ca/wpcontent/uploads/2019/05/Petrarca Kitchen CATE ITE Ontario July 2017 final.pdf

Preissle, J., \& Roulston, K. (2009) Trends in teaching qualitative research: A 30-year perspective. In M. Garner, C. Wagner \& B. Kawulich (Eds.), Teaching research methods in the social sciences (1322), Farnham: Ashgate Publishing Group.

Prewitt, V. (2011). Working in the cafe: Lessons in group dialogue. The Learning Organization, 18(3), 189-202.

Reis-Jorge, J. (2007) Teachers' conceptions of teacher-research and self-perceptions as enquiring practitioners: A longitudinal case study. Teaching and Teacher Education: An International Journal of Research and Studies, 23(4), 402-417.

Rudduck, J. (1985) Teacher research and research-based teacher education. Journal of Education for Teaching, 11(3), 281-289. https://doi.org/10.1080/0260747850110305

Saeed, M. A. \& Ghazali, K. (2019) Engaging postgraduates in a peer research group at the research proposal stage in a Malaysian university: Support and challenges. Teaching in Higher Education, 24(2), 180-196. https://doi.org/10.1080/13562517.2018.1471458 


\section{Dialogic pedagogy in graduate teacher education research advisement Victorina Baxan, Joanne Pattison-Meek, Andrew B. Campbell}

Saldaña, J. (2009) Popular film as an instructional strategy in qualitative research methods courses. Qualitative Inquiry, 15(1), 247-261.

Samaras, A.P., \& Freese, A. R. (2009). Looking back and looking forward: An historical overview of the self-study school. In C.A. Lassonde, S. Galman, \& C. Kosnik (Eds.), Self-study research methodologies for teacher educators (pp. 3-19). Boston: Sense Publishers.

The World Café Community Foundation (2015). A quick reference guide for hosting World Café. Retrieved from http://www.theworldcafe.com/wp-content/uploads/2015/07/Cafe-To-GoRevised.pdf

Thien, D. (2009) Encouraging gender analysis in research practice. Journal of Geography in Higher Education, 33(3), 351-367.

Wagner, C., Garner, M. \& Kawulich, B. (2011). The state of the art of teaching research methods in the social sciences: Towards a pedagogical culture. Studies in Higher Education, 36(1), 75-88. https://doi.org/10.1080/03075070903452594

Wells, G. (1999). Dialogic inquiry: Towards a sociocultural practice and theory of education. New York, NY: Cambridge University Press.

Wilmot, K. (2016). Designing writing groups to support postgraduate students' academic writing: A case study from a South African University. Innovations in Education and Teaching International, 8, 19.

Yu, S., \& Hu, G. (2017). Can higher-proficiency L2 learners benefit from working with lower-proficiency partners in peer feedback? Teaching in Higher Education 22(2), 178-192.

\section{(cc) EY}

New articles in this journal are licensed under a Creative Commons Attribution 4.0 United States License.

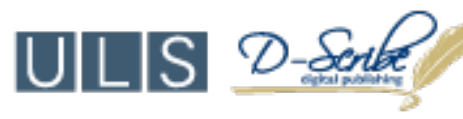

This journal is published by the University Library System, University of Pittsburgh as part of its D-Scribe Digital Publishing Program and is cosponsored by the University of Pittsburgh Press. 